\title{
LA DIGITALIZACIÓN DEL TRABAJO Y SU INCIDENCIA EN LOS DERECHOS COLECTIVOS DE LOS TRABAJADORES ${ }^{1}$
}

\author{
Esther Guerrero Vizuete ${ }^{2}$ \\ Profesora Contratada Doctora (acreditada) \\ Departamento de Derecho Público, Universitat Rovira i Virgili
}

\begin{abstract}
Las empresas adoptan nuevas estructuras en las que el uso de las tecnologías de la información está cada vez más presente. En esta realidad económica están teniendo una gran influencia las plataformas digitales, especialmente las integradas bajo el término crowdsourcing, las cuales ofrecen servicios en el mercado a través de sujetos cuya calificación jurídica está aún por determinar. Esta circunstancia influye notoriamente no solo en las condiciones laborales de los trabajadores que prestan servicios en el ámbito de la economía de las plataformas sino también tiene una especial incidencia en el ámbito de la protección colectiva. El presente trabajo se propone analizar la incidencia que las nuevas formas de empleo están teniendo en determinados aspectos vinculados a la protección colectiva de los trabajadores.
\end{abstract}

Companies adopt new structures in which the use of information technologies is increasingly present. In this economic reality, digital platforms are obtaining great influence, especially those integrated under the term crowdsourcing, which offer services in the market through workers whose legal qualification is yet to be determined. This circumstance notoriously influences, not only on working conditions of workers who provide services in the field of the platform economy, but it also has a special impact on the field of collective protection. This paper proposes to analyze the incidence that new forms of employment have in certain aspects linked to the collective protection of workers.

IUSLabor 1/2019, ISSN 1699-2938, p. 267-286.

DOI. 10.31009/IUSLabor.2019.i01.06

Title: Digitalization of work and its incidence on worker's collective rights

\footnotetext{
${ }^{1}$ Este artículo se ha elaborado en el marco del Proyecto de I+D+I titulado "La representación laboral en las empresas dispersas y en red: problemática, disfunciones y propuestas correctoras" financiado por el Ministerio de Economía y Competitividad (DER 2017- 83189-R). IP Xavier Solà Monells y Ricardo Esteban Legarreta

2 esther.guerrero@urv.cat; Orcid: 0000-0001-9710-4823.
} 
Palabras clave: Trabajo digital, economía colaborativa, derechos colectivos de los trabajadores

Keywords: Digital work, collaborative economy, worker's collective rights

\section{Sumario}

1. Las nuevas formas de trabajo en el contexto de la economía digital: las prestaciones basadas en micro tareas o el nuevo taylorismo

1.1 ¿Trabajadores autónomos o dependientes? La necesaria calificación jurídica de los prestadores de servicios a través del crowdsourcing on-line

2. La articulación de la acción colectiva y sus problemas de encaje ante los nuevos modelos de negocio

2.1. La autonomía colectiva de los trabajadores autónomos en el ámbito de la economía de las plataformas

2.2. La compleja delimitación de la estructura representativa de los trabajadores digitales

3. ¿Es posible una negociación colectiva sin adjetivos? El convenio colectivo como instrumento homogeneizador de las nuevas formas de empleo

4. Bibliografía 


\section{Las nuevas formas de trabajo en el contexto de la economía digital: las prestaciones basadas en micro tareas o el nuevo taylorismo}

La crisis económica sufrida y los avances tecnológicos alcanzados han dado lugar a lo que se ha venido en llamar economía digital, término con el se pretende abarcar las transformaciones que la digitalización está produciendo en el mundo del trabajo. Asistimos así a un fenómeno que está produciendo importantes cambios no solo a nivel productivo sino también en la forma como se están vinculando empleadores y trabajadores

En el contexto de la economía digital podemos distinguir dos tipos de economía: la economía colaborativa (sharing economy) y la economía bajo demanda (economy on demand). Con el término de economía colaborativa se pretenden englobar distintos modelos de negocio que no responden ni al concepto en el que se les incardina ni a la novedad que se les atribuye. La economía colaborativa se dirige a proporcionar a un bien infrautilizado una mayor vida útil, siendo cedido por su titular a quien con carácter ocasional o intermitente lo necesita ${ }^{3}$. En su esencia responde a un intercambio entre particulares $^{4}$. Por su parte en la economía bajo demanda se integran aquellas plataformas que disponen "de un buen número de prestadores de servicios, los cuales están a la espera de que un consumidor solicite un servicio" "Su formulación no es en absoluto novedosa al reflejar el espíritu de la tradicional economía capitalista ${ }^{6}$. La novedad reside en que "la competencia se desplaza de empresas estructuradas a microempresarios, que no teniendo por qué respetarla, pueden ser conducidos a fenómenos de autoexplotación" ". Recurren, en muchas ocasiones de forma fraudulenta,

\footnotetext{
3 "En sentido estricto, la economía colaborativa exige para ser considerada como tal que la actividad sea sin ánimo de lucro o, como mucho, esté inspirada en los principios de la economía social, y esté pensada realmente para compartir gastos entre los usuarios de un determinado servicio o intercambiar productos infrautilizados". SÁNCHEZ-URÁN AZAÑA, Y., "Economía de plataformas digitales y servicios compuestos. El impacto en el Derecho, en especial, en el Derecho del Trabajo", La Ley Unión Europea, $\mathrm{n}^{\mathrm{o}}$ 57, 2018, p. 4 (versión digital La Ley).

${ }^{4}$ SORIA BARTOLOMÉ señala entre las características de este modelo el hecho de que "en la economía colaborativa prestadores y usuarios son de tamaño y capacidad de negociación similar ...el volumen de su actividad es de pequeño tamaño y las transacciones de poco importe". SORIA BARTOLOMÉ, B., "Aspectos económicos de la economía colaborativa", en MONTERO PASCUAL (Director), La regulación de la economía colaborativa. Airbnb, Blabacar, Uber y otras plataformas, Tirant lo Blanch, Valencia, 2017, p. 79-81.

${ }^{5}$ Todolí Signes, A., El trabajo en la economía colaborativa, Tirant lo Blanch, Valencia, 2016, p. 21.

${ }^{6}$ Señala AGOTE que "[1]a idea de ofrecer un producto o un servicio ajustándose a las necesidades del cliente final es en sí la base de la economía capitalista. Toda economía capitalista ha sido y es una economía "a la demanda". AGOTE, R., "On demand economy: 10 claves de entendimiento laboral", Iuslabor, $\mathrm{n}^{\circ} 1,2017$, p. 3.

${ }^{7}$ Dagnino, E., "Uber Law: perspectiva jurídico-laboral de la sharing/on demand economy", Revista Internacional y Comparada de Relaciones Laborales y Derecho del Empleo, nº 3, 2015, p. 26.
} 
al trabajo autónomo como forma de vinculación contractual persiguiendo una reducción de costes y de posible conflictividad laboral amparada en la mayor protección que el ordenamiento jurídico dispensa a los trabajadores asalariados. Una problemática que no se centra únicamente en el terreno de la protección social, sino que también está originando preocupantes fenómenos de economía sumergida y evasión fiscal.

La rapidez de su desarrollo, gracias a las plataformas electrónicas que posibilitan ese intercambio, está derivando, sin embargo, en una nueva forma de producción y distribución de bienes y servicios en la que las empresas tradicionales están siendo desplazadas por entes etéreos y por personas que ostentan el doble rol de proveedor y de consumidor. $\mathrm{Y}$ es precisamente en ese doble componente subjetivo e instrumental donde reside la novedad. Como señala MONTERo PASCUAL, nuestro sistema legal está basado en la profesionalidad por lo que en él no está teniendo un adecuado encaje el creciente protagonismo de estas personas físicas que de forma no habitual ofertan bienes y servicios ${ }^{8}$. La facilidad con la que cualquier persona puede convertirse en prestadora definiendo autónomamente la duración y alcance de su actividad trae consigo como premisa de partida problemas de calificación jurídica. Al mismo tiempo, el instrumento del que se sirven estos nuevos modos de satisfacer las necesidades de los consumidores, la plataforma electrónica, plantea la necesidad de delimitar si estamos ante un simple servicio de mediación o bien se trata de una empresa verticalmente integrada. Unos problemas que deben ser abordados teniendo en cuenta que la diversidad de plataformas existentes exige clarificar en primer término su naturaleza, identificando así su modelo de negocio, para proceder posteriormente a delimitar el vínculo que las une con sus prestadores.

Actualmente existen multitud de plataformas digitales que prestan servicios (crowdwork $o$ crowdsourcing) de forma presencial (off-line) o de forma virtual (on-line). El Crowdsourcing off line supone la prestación de servicios de forma presencial, con un carácter local y siendo sus destinatarios los consumidores finales. Se integran en este modelo plataformas como Listminut, Deliveroo, Glovo, Sandeman, Helpling, Etece, Trabeja.com o Taskia, entre otras. El Crowdsourcing on line es un modelo de negocio consistente en la descentralización de una actividad entre una multitud de prestadores de forma que cada uno de ellos lo que realiza es una micro tarea, una ínfima fracción de actividad que requiere un tiempo de realización breve y cuya forma de retribución es el destajo. Se trata de una prestación de servicios desarrollada con carácter global, es decir, deslocalizada, en la que el destinatario final son las empresas. El prestador es un trabajador virtual, anónimo, que decide en cada momento qué micro tareas van a

\footnotetext{
${ }^{8}$ Montero Pascual, J. J., "La regulación de la economía colaborativa", en Montero Pascual (Director), La regulación de la economía colaborativa. Airbnb, Blabacar, Uber y otras plataformas, Tirant lo Blanch, Valencia, 2017, p. 33.
} 
realizar. Exponente de este modelo es Amazon Mechanical Turk. A través de esta plataforma las empresas clientes obtienen una fuerza de trabajo ampliable y bajo demanda. Para ello basta delimitar la tarea a realizar y el precio de esta. Así, si se requiere su realización en un corto periodo de tiempo la empresa puede conseguir un mayor número de operarios (turkers) interesados elevando la cantidad a pagar por la micro tarea. Son operaciones sencillas y repetitivas que el hombre realiza mejor que un ordenador, de ahí que no haya sido sustituido por la inteligencia artificial como está sucediendo en otros ámbitos. De este modo, las HIT (Human Intelligence Tasks) pueden consistir en la descripción de un objeto, la identificación de la composición de un producto, la traducción de varias líneas de un texto, la identificación de productos duplicados en catálogos on line o la verificación de datos de un restaurante (número de teléfono, dirección, horario etc.). Asimismo, son tareas de muy corta duración temporal que una vez finalizadas son de nuevo enviadas a la plataforma para su recepción por la empresa cliente. Amazon realiza una previa clasificación tanto de las tareas (en base a su temática) como de los prestadores (en base a las puntuaciones obtenidas en tareas anteriores) asegurando así una adecuada realización en términos de calidad e impidiendo que clientes y prestadores puedan establecer contactos contractuales fuera de la propia plataforma?

De este modo, merced a las nuevas tecnologías, asistimos al retorno del taylorismo como técnica de organización de trabajo en el que la subdivisión de las tareas a realizar permite aumentar la productividad al tiempo que evita todo control por parte del trabajador de los tiempos de producción. Entre sus efectos negativos se señalan la descualificación profesional del trabajador, al no ser necesario una especial formación para su realización al tiempo que no se le proporciona una experiencia profesional de calidad $^{10}$.

Centrando nuestro trabajo en la prestación de servicios a través del Crowdsourcing on line y en un plano estrictamente jurídico, la proliferación de este tipo de plataformas ha dado lugar a una importante transformación de la figura del prestador del servicio. Frente a un trabajador individualizable, que ejecuta su prestación en un entorno físico definido y bajo unas condiciones laborales predeterminadas que fijan sus derechos y obligaciones, asistimos al nacimiento de un nuevo tipo de trabajador, el trabajador digital, deslocalizado física y geográficamente, sujeto a prestaciones fraccionadas y

\footnotetext{
${ }^{9}$ Una condición similar es impuesta por The work crowd la cual exige a la empresa cliente, si se produce esa circunstancia, el pago del $20 \%$ de las ganancias del trabajador durante 52 semanas. Información disponible en theworkcrowd.com.

${ }^{10}$ Algunos autores advierten del peligro de infra cualificación que se exige pues "[1] a descomposición de este trabajo en pequeñas unidades sin sentido en sí mismas podría dar lugar a un acceso universal a este tipo de trabajo, con independencia de la formación y perfil profesional del trabajador". TRILLo, F., "Relaciones de trabajo en la economía digital", Revista de Derecho Social, nº 76, 2016, p.4.
} 
micro remuneradas que complican extraordinariamente su encaje legal. Unas dificultades que en gran parte vienen motivadas por querer encuadrar jurídicamente estas prestaciones siguiendo los presupuestos que tradicionalmente han definido la laboralidad, como tendremos ocasión de analizar en las líneas siguientes. Un trabajador digital que, además, al no estar vinculado con carácter exclusivo al empleador, puede modificar con extraordinaria libertad el contenido y el titular de las prestaciones que realiza dando lugar a lo que se ha venido en denominar trabajadores nómadas.

\section{1 ¿Trabajadores autónomos o dependientes? La necesaria calificación jurídica de los prestadores de servicios a través del crowdsourcing on-line}

El trabajador digital nace como una forma híbrida de prestador de servicios ${ }^{11}$. Sus notas características pueden ser encuadrables tanto en el ámbito del trabajo por cuenta ajena como en el del trabajo por cuenta propia, dependiendo, a falta de una regulación legal que los defina, del sentido y alcance que se impriman a la forma cómo se manifiestan en cada caso concreto las notas caracterizadoras de uno u otro. A título ejemplificativo, mientras que para unos la libertad de trabajo de la que gozan estos trabajadores es un rasgo identificativo de su independencia y por tanto de su encaje en el ámbito del Derecho Privado $^{12}$, para otros tal libertad no existe, estando el trabajador sometido a una dependencia digital intensa merced precisamente a las nuevas tecnologías que hacen posible el desarrollo de su actividad, por lo que no hay duda de su encaje en el ámbito protector del Derecho del Trabajo ${ }^{13}$.

La delimitación de su naturaleza jurídica se está realizando tomando como punto de partida las nociones clásicas de dependencia y ajenidad, aun cuando es de general

\footnotetext{
11 "Este tipo de homo faber tiene la capacidad suficiente para instalarse como autónomo y la fragilidad inevitable para recaer como subordinado en una o varias empresas de inciertas características, de donde es un desarraigado económico cuya patria no es el contrato ni la profesión, sino la sociedad". OjEDA AviLÉs, A., La deconstrucción del Derecho del Trabajo, La Ley, Madrid, 2010, p. 103.

${ }^{12}$ En esta línea se sitúan, entre otros, MERCADER UguinA, J. R., "El nuevo modelo de trabajo autónomo en la prestación de servicios a través de plataformas digitales", Diario La Ley, n 9, 2017; MONTERO PASCUAL, J. J., "La regulación de la economía colaborativa", op. cit., p. 43; GuERRERo VizUETE, E., "La economía digital y los nuevos trabajadores: un marco contractual necesitado de delimitación", Revista de Relaciones Laborales y Derecho del Empleo, vol. 1, nº $1,2018$.

${ }^{13}$ En esta línea de opinión se encuadran, entre otros, GINÈs I FABRELLAS, A., "Crowdsourcing sites y nuevas formas de trabajo. El caso de Amazon Mechanical Turk", Revista Derecho Social y Empresa, $\mathrm{n}^{\circ}$ 6, 2016, p. 82; Beltrán DE Heredia Ruíz, I., "Economía de las plataformas y contrato de trabajo", Ponencia realizada en las XXIX Jornadas Catalanas de Derecho Social, Barcelona, 2018, Blog "Una mirada crítica a las relaciones laborales" [en línea], Disponible en https://ignasibeltran.com/2018/02/07/economia-de-las-plataformas-platform-economy-y-contrato-detrabajo-ponencia/; SÁNCHEZ-URÁN AZAÑA, Y., "Economía de plataformas digitales y servicios compuestos...", op. cit., p. 17.
} 
aceptación que estos nuevos modelos de negocio no responden a los planteamientos del tipo de empresa al abrigo del cual aquellas nociones fueron formuladas. Este desfase conceptual trae consigo un panorama de inseguridad en el que los rasgos identificadores del trabajo asalariado, especialmente en lo referente a la dependencia, están siendo objeto de una extraordinaria flexibilización tanto por vía doctrinal como jurisprudencial, hasta el punto de poder hablar de un amplio impulso hacia la laboralización de estos nuevos trabajadores como instrumento clave en orden a proporcionarles una suficiente protección. De este modo, tomando como punto de partida el micro trabajo on-line, la libertad que tiene el prestador en la determinación de los días concretos en los que va a trabajar, la selección de la/s tarea/s a realizar y la duración de su prestación son señaladas como una muestra más de la flexibilidad con la que debe ser entendida la noción de dependencia teniendo en cuenta el actual contexto económico y productivo. Sin embargo, debe tenerse en cuenta que esa libertad decisoria no es un elemento propio del contrato de trabajo al "no existir en España la posibilidad de que un contrato de trabajo se active o desactive a voluntad del trabajador" $"$. A ello debe añadirse la libertad de la gozan a la hora de decidir quién será su empleador. Se trata de un poder de decisión definitorio del trabajo por cuenta propia que en modo alguno puede hacerse extensivo al ámbito del trabajo asalariado. En consecuencia, todas aquellas prestaciones de servicios que se encuentran intervenidas por las plataformas al ser ellas las que fijan la jornada del prestador, su horario, los tiempos de presencia etc., deben ser calificadas como laborales al responder a supuestos de falsa autonomía. Y a sensu contrario cuando el trabajador decide con total autonomía en qué momentos va a trabajar, durante cuánto tiempo, para quién y con qué tipo de prestación, su actividad debe ser calificada como extralaboral.

Junto a la laxitud en la gestión del tiempo de trabajo, se ha señalado como elemento integrante de la subordinación el control digital que la plataforma ejerce sobre el prestador. Su finalidad no es otra que supervisar la satisfacción final del cliente, y en base a la cual, se producirán o no sucesivas relaciones contractuales con otros empleadores-clientes que se integren en la plataforma. Actúan así a modo de "filtro" facilitando la selección de prestadores para proporcionar fuerza de trabajo a futuros clientes-empresas. De este modo, en el trabajo digital el prestador no es ajeno al riesgo. Antes al contrario. La calidad de su prestación es la herramienta que le proporcionará una expectativa de mayores réditos. La novedad reside en que una actividad inclusiva o excluyente que hasta ahora ha sido realizada de forma natural por el propio mercado pasa a ser realizada por un algoritmo integrado en una plataforma digital tomando como base la información que los propios sujetos facilitan. El problema no está, por tanto, en que la valoración positiva de un determinado servicio sea tomada como referencia para determinar la cualificación del trabajador condicionando así el acceso a mejores

${ }^{14}$ AgOte, R., "On demand economy...", op. cit., p. 14. 
prestaciones o micro tareas. El problema reside en lo que se exige al prestador para poder alcanzar el umbral que le permitirá seguir siendo parte de esa relación contractual. Es ahí donde debemos situar el punto de partida, pues al margen de la calificación jurídica del prestador como trabajador por cuenta ajena o por cuenta propia, debería abordarse la fijación de unos mínimos de contratación que eviten la devaluación de las condiciones en que ese trabajo se presta ${ }^{15}$.

La deslocalización de los trabajadores, la falta de una normativa legal que determine a qué categoría jurídica pertenece y a qué tipo de protección social pueden acceder están provocando un déficit de atención de un elevado número de trabajadores. Tanto si tomamos como referencia a quienes prestan sus servicios a través del crowdsourcing off-line, es decir de forma presencial, como on-line, esto es de forma virtual, ya sean calificados como trabajadores asalariados o autónomos, su denominador común es la ausencia de una adecuada protección tanto en el plano individual como en el ámbito de la acción y defensa colectivas. La desconexión de la regulación legal respecto al fenómeno del trabajo digital y, sobre todo, su lenta respuesta habida cuenta de que cada vez afecta a un mayor número de personas, no queda referida solo a la determinación del nomen iuris y su correspondiente régimen jurídico; es también apreciable en el terreno de la defensa colectiva, ámbito en el que hace tiempo, y en relación a otros modelos de negocio (grupo de empresas, empresas en red, empresas multiservicios...) la doctrina más autorizada viene reclamando una actualización del Título II del Estatuto de los Trabajadores.

Ahí reside, en nuestra opinión, el verdadero problema en estos nuevos modelos de negocio: junto a la ausencia de identidad profesional del prestador, la ausencia de una respuesta legislativa también está provocando una desorganización en la defensa colectiva de sus intereses que ralentiza la respuesta social.

\section{La articulación de la acción colectiva y sus problemas de encaje ante los nuevos modelos de negocio}

La anomia legal manifestada en el ámbito de las relaciones individuales se ve complementada por una desactualización de la normativa que regula la acción y defensa colectivas de los trabajadores en general, y de quienes prestan sus servicios para plataformas digitales, en particular. De este modo, tanto si el trabajador llega a ser

\footnotetext{
${ }^{15}$ Una queja común manifestada por trabajadores que prestan servicios tanto en plataformas de Crowdsourcing off line como Deliveroo como en plataformas de crowdsourcing on-line como Amazon Mechanical Turk es la dilatada jornada de trabajo que deben realizar para obtener unos ingresos mínimos suficientes.
} 
finalmente calificado como asalariado ${ }^{16}$ como si ejerce su prestación en calidad de autónomo $^{17}$, opción por la que nos decantamos en el ámbito del Crowdsourcing on line $\mathrm{y}$ en muchos de los supuestos de prestación off-line, la defensa colectiva de sus necesidades choca con una normativa necesitada de reformulación motivada en gran medida por su falta de encaje en los nuevos escenarios económico-productivos que surgen y en los presupuestos en los que se asientan.

\subsection{La autonomía colectiva de los trabajadores autónomos en el ámbito de la economía de las plataformas}

Siendo el trabajo autónomo la forma habitual de encuadrar jurídicamente a los prestadores de servicios en las plataformas digitales conviene analizar en primer término los cauces a través de los que se regula su acción y defensas colectivas.

El artículo 28.1 CE sitúa entre los derechos fundamentales el derecho a sindicarse libremente si bien, en relación a los trabajadores autónomos, su norma de desarrollo expresa ese reconocimiento de una forma más limitada, al señalar que el derecho de Libertad sindical de quienes desarrollan una prestación de servicios con autonomía y sin ajenidad queda constreñido al derecho de afiliación a sindicatos ya constituidos siempre que no ostenten la condición de empleadores, es decir, cuando no tengan asalariados a su cargo (artículo 3.1. LOLS). Una previsión que, como ya advirtiera CRUZ VILLALón, ha colocado a los trabajadores autónomos en una posición de marginalidad en el seno de estas organizaciones al carecer este colectivo de valor estratégico para el sindicato ${ }^{18}$. Ese escaso interés que el sindicato tenía para los trabajadores autónomos trató de ser paliado por la Ley 20/2007 de 11 de julio, reguladora del Estatuto del Trabajo Autónomo (LETA) atribuyéndoles un derecho de fundación y afiliación a asociaciones profesionales destinadas específicamente a la defensa de sus intereses. De este modo, quedó instaurada una doble vía representativa: por un lado, un derecho de afiliación sindical limitado a quienes no dispusieran de trabajadores asalariados y por otro, un

\footnotetext{
${ }^{16}$ Hasta la fecha las dos únicas sentencias dictadas en este sentido son las del Juzgado de lo social de Madrid de 22 de marzo de 2018 (Rec. 971/2017) y la del Juzgado de lo social de Valencia de 1 de junio de 2018, (Rec. 633/2017), que declaran la laboralidad de los trabajadores en las plataformas Take Eat Easy y Deliveroo respectivamente.

${ }^{17}$ La reciente SJS $n^{\circ} 39$ de Madrid de 3 de septiembre de 2018 declara la condición de trabajador por cuenta propia de un repartidor de Glovo, entendiendo que en el caso planteado concurren las notas características de la relación TRADE.

18 CruZ Villalón, J., "La tutela colectiva por los trabajadores autónomos de sus intereses profesionales", Relaciones Laborales, $\mathrm{n}^{\circ}$ 7, 1999, p. 11 (versión digital). Esta circunstancia puede obedecer a que la representatividad sindical, la cual le otorga una posición jurídica singular, se sustenta en los resultados obtenidos en las elecciones a representantes unitarios, ámbito del que los trabajadores autónomos están excluidos.
} 
derecho de asociación profesional amplio tanto con relación a quienes sean sus titulares como al alcance de su acción colectiva (artículo 19 LETA).

Con el reconocimiento de las asociaciones profesionales de trabajadores autónomos la LETA abrió la puerta a una defensa colectiva más específica, cuyos destinatarios potenciales serían aquellos trabajadores autónomos que no respondían al perfil de empresarios, y cuyos intereses profesionales no quedaban adecuadamente representados a través de las asociaciones empresariales. De este modo, se arbitró en realidad una tercera vía de representación, pues hasta entonces el asociacionismo empresarial al amparo del artículo $22 \mathrm{CE}$ se constituía en la fórmula alternativa para aquellos trabajadores autónomos que, aun no teniendo trabajadores a su cargo, optaban por no confiar su defensa colectiva a los sindicatos ya constituidos conforme a lo postulado por el artículo 3.1. $\operatorname{LOLS}^{19}$.

A pesar de esta triple vía representativa, la realidad nos muestra que, en el supuesto concreto de los trabajadores que prestan servicios para plataformas digitales, el camino por el que se ha optado es tangencial, quizá como apunta algún sector doctrinal motivado por "el desapego creciente que expresan algunos sectores o subsectores de actividad hacia las centrales (sindicales) más consolidadas" ${ }^{20}$. De este modo, en lugar de recurrir a formas clásicas de organización para que les representen y reclamen mejoras colectivas en sus condiciones de trabajo, se está recurriendo a formas no convencionales para luchar contra la precariedad que lleva implícita la economía digital. Muestra de ello son las plataformas de peticiones como coworker.org a través de las cuales se puede plantear de forma pública una petición destinada a mejorar un aspecto determinado del lugar de trabajo o de las condiciones de trabajo a la que pueden adherirse los demás trabajadores de la empresa; o los foros de reunión en los que los trabajadores exponen sus experiencias laborales, las cuales pueden servir a su vez para denunciar las concretas condiciones en las que éstas se desenvuelven. Un ejemplo significativo por su importancia dada la dispersión y el anonimato social al que se encuentran sometidos los micro trabajadores de la plataforma Amazon Mechanical Turk es Turkopticon, un instrumento a través del cual intercambian experiencias además de valorar a los clientes proporcionando así información sobre la identidad de los que conviene evitar ${ }^{21}$, o Dynamo, que bajo el lema "Impulsando el cambio en Mturk"

${ }^{19}$ GUERRERo VizUETE, E., El trabajador autónomo dependiente económicamente: un estudio jurídico laboral, Lex Nova- Thomson Reuters, Valladolid, 2012, p. 248-254.

${ }^{20}$ Entre otros, Esteban LegarRetA, R., "Cuestiones sobre la articulación de la representación del personal al servicio de plataformas colaborativas", en Descentralización productiva: nuevas formas de trabajo y organización empresarial, Cinca, Madrid, 2018, p. 6.

${ }^{21}$ La operativa de Amazon Mechanical Turk permite a un cliente no abonar el precio del trabajo realizado cuando considere que el resultado no es el satisfactorio. Frente a la negativa al pago, el trabajador no tiene opción alguna para reclamar. 
persigue la acción colectiva para conseguir mejoras en las condiciones contractuales de estos trabajadores $^{22}$. En otras ocasiones son los contenidos publicados a través de las redes sociales los que promueven cambios en las empresas ante el temor de sufrir boicots por parte de los clientes ${ }^{23}$ o incluso dan lugar a plataformas paralelas en las que ejercer la misma prestación bajo unas condiciones laborales más dignas ${ }^{24}$.

Estos ejemplos muestran que el movimiento sindical, está tardando en responder a las necesidades laborales que los cambios tecnológicos están planteando. Entre las escasas iniciativas existentes figura la elaborada por $\mathrm{UGT}^{25}$ en la que se aborda el planteamiento de demandas colectivas contra las plataformas digitales, en lugar de demandas individuales, y la constitución de secciones sindicales en el seno de estas para facilitar la participación de los afectados.

\subsection{La compleja delimitación de la estructura representativa de los trabajadores digitales}

Al abordar la cuestión relativa a la posible organización colectiva de quienes prestan servicios a través de plataformas digitales, dos son las interrogantes que surgen de inmediato: ¿cómo unir lo disperso? Y ¿es posible organizar una voz y respuesta colectivas al amparo de la normativa existente?

En respuesta a la primera de las interrogantes planteadas, y al margen de la condición de asalariado o autónomo que se atribuya a los trabajadores digitales, la instancia representativa común que puede englobar a la inmensa mayoría de estos trabajadores es el sindicato, centralizando a un colectivo muy heterogéneo de representados y cuyos intereses, no obstante, son homogéneos: la lucha contra la precariedad laboral mediante el establecimiento de condiciones de trabajo más dignas. La integración y gobernabilidad son, sin embargo, cuestiones que no encuentran un adecuado acomodo en la normativa actual. La instancia representativa primaria por la que apostó el ET tiene su base en el concepto de centro de trabajo, una noción que plantea dificultades en

\footnotetext{
${ }^{22}$ Accesible en www.wearedynamo.org.

${ }^{23}$ La publicación de un vídeo en la que se realizaba una detención de dos hombres negros que esperaban a un amigo en una cafetería de la empresa Starbucks en Filadelfia provocó protestas frente al local y llamadas a boicotear el consumo en esa cadena. El resultado fue el cierre de 8.000 cafeterías durante parte de una jornada de trabajo con el fin de proporcionar a los trabajadores una mejor formación sobre prejuicio racial. Noticia publicada en www.cnnespanol.cnn.com el 18 de abril de 2018.

${ }^{24}$ Es el caso de Mensakas, cooperativa de pedidos online y entrega a domicilio constituida en abril de 2018 e integrada por ex trabajadores de Deliveroo y Glovo agrupados en la plataforma Riders por Derechos.

${ }^{25}$ Recogidas en el documento Estrategia ante la situación del empleo en las plataformas digitales de 1 de agosto de 2018, disponible en www.ugt.es.
} 
su dimensión perimetral y personal cuando el trabajo se desarrolla mediante plataformas digitales. Con relación a los contornos del concepto, el artículo 1.5 ET define el centro de trabajo como una unidad productiva con organización especifica que sea dada de alta como tal ante la autoridad laboral, requisito este último de carácter meramente formal ${ }^{26}$. La referencia legal a la organización especifica debe ser entendida en el sentido de autonomía organizativa. Si bien en las empresas tradicionales la identificación física del centro de trabajo no plantea especiales problemas, no ocurre lo mismo cuando la condición de empleador se pretende atribuir a un ente etéreo como es una plataforma digital. En estos nuevos modelos de negocio debe atenderse como indica GARRIDO PÉREZ a "la concreta unidad organizativa prestacional de la aplicación, delimitado por un entorno físico o territorial de operatividad, a la que se adscriben los trabajadores que prestan el servicio que la plataforma o aplicación ofrece ${ }^{\text {,27 }}$. Mayores dificultades surgen al abordar la adscripción de los trabajadores al centro de trabajo a efectos de designar a sus representantes unitarios. Aspectos tales como el número de representantes a elegir o la identificación de los electores y elegibles teniendo en cuenta que el ET pone el acento en la antigüedad del trabajador y no en el tiempo de prestación de servicios (artículo69.2) comprometen la efectividad de esta instancia representativa. Unos obstáculos que se acentúan cuando la prestación de servicios se realiza on-line y la deslocalización provoca un individualismo peligrosamente aislacionista en los trabajadores, que juega en beneficio de las empresas propietarias de las plataformas digitales, en una suerte de actualización de la máxima latina divide ut imperes.

Las dificultades apuntadas hacen que la representación sindical configurada en la LOLS sea la mejor alternativa a la falta de protección colectiva de estos trabajadores. La afiliación de quienes prestan servicios digitales, ya sean asalariados o autónomos en los términos antes señalados a un sindicato, permitirá la constitución de secciones sindicales en el seno de la plataforma digital ya sea entendida como empresa o como centro de trabajo. En este caso las dificultades de integración de los trabajadores en estas estructuras representativas se diluyen al estar reguladas con un carácter extraordinariamente amplio: el único límite viene dado por el cumplimiento de lo que al

\footnotetext{
${ }^{26}$ La STS de 24 de febrero de 2011 (Rec. 1764/2010) señala que el alta no es un elemento constitutivo y que lo decisivo es que se aprecie la existencia de una unidad técnica de producción, que, dentro del conjunto de la actividad de la empresa, sirva a la ejecución práctica de ésta.

Sobre la problemática que plantea la delimitación del centro de trabajo vid Álvarez Del CuviLlo, A., "El centro de trabajo como unidad electoral: un concepto jurídico indeterminado en un contexto de cambio organizativo", Revista Española de Derecho del Trabajo, nº 88, 2016.

${ }^{27}$ Señala la autora que "aún siendo la aplicación única en su conformación técnica, no lo es desde el punto de vista de la organización y gestión concreta del servicio que ofrece puesto que ello dependerá del ámbito territorial donde se proyecta particularmente la aplicación". GARRIDO PÉREZ, E., "La representación de los trabajadores al servicio de plataformas colaborativas", Revista de Derecho Social, no 80, 2017, p. 221.
} 
efecto dispongan sus Estatutos (artículo 8. 1.a. LOLS). No se requiere que el sindicato al que la sección sindical pertenezca tenga una determinada implantación, admitiéndose esta posibilidad incluso si su representatividad fuera prácticamente nula, cuestión que enlaza con la exclusión de los trabajadores autónomos del cómputo de la representatividad a través de la audiencia electoral. Se contaría así con un interlocutor válido aun cuando, de nuevo, su efectividad práctica quede mermada por la "dependencia" que la legitimación negociadora tiene respecto de los órganos de representación unitarios.

Los problemas apuntados que dificultan la integración de los trabajadores digitales en las tradicionales estructuras representativas deben hacernos volver la vista hacia la literalidad del artículo 61 ET, el cual al configurar la representación unitaria como vía de realización del derecho de los trabajadores a participar en la empresa alude a la posible existencia "de otras formas de participación". Una previsión hasta la fecha no explorada que bien podría servir para dar un adecuado encaje a las necesidades representativas de estos trabajadores.

\section{3. ¿Es posible una negociación colectiva sin adjetivos? El convenio colectivo como instrumento homogeneizador de las nuevas formas de empleo}

El debate sobre la naturaleza jurídica del trabajo en plataforma digitales provoca que la negociación para la mejora de sus condiciones contractuales pueda materializarse en instrumentos de distinto alcance. Algunas prestaciones de servicios ya están siendo calificadas como laborales por lo que su encaje en el ámbito de un convenio colectivo no ofrece lugar a dudas. Otras, sin embargo, siguen siendo a priori calificadas de autónomas derivando, cuando esa autonomía va acompañada de una dependencia económica, en una negociación de las concretas condiciones en las que se desarrollarán las prestaciones de servicios por medio de un Acuerdo de Interés Profesional ${ }^{28}$. Sin embargo, respecto de quienes son autónomos $\sin$ asalariados y sin dependencia económica, la articulación de su defensa colectiva no está tan clara, siendo preciso abordar la cuestión de su posible integración en el ámbito de aplicación de los convenios colectivos cuando se encuentran afiliados a la organización sindical negociadora conforme al artículo 3.1. LOLS. Una posibilidad que, en opinión de SÁEZ LARA ayudaría a que los convenios colectivos pudieran ofrecer soluciones ajustadas a

\footnotetext{
${ }^{28}$ Sirva de ejemplo el Acuerdo de Interés Profesional suscrito por la Asociación Española de riders mensajeros (ASO riders) y Deliveroo que entró en vigor el 16 de julio de 2018 y en el que, entre otras mejoras, se prevé una indemnización por extinción del contrato sin causa por parte de la empresa Deliveroo o la interrupción justificada de la actividad en los supuestos de lluvia, viento o nieve calificada como alerta naranja o roja por la Agencia Estatal de Meteorología.
} 
las necesidades de los trabajadores autónomos ${ }^{29}$, máxime si tenemos en cuenta que ya no es nada infrecuente que trabajadores asalariados y trabajadores autónomos realicen la misma actividad, para el mismo empresario y bajo condiciones contractualmente semejantes. Esta realidad está siendo reflejada en algunos convenios colectivos sin bien de forma muy parcial ${ }^{30}$, de ahí que debamos preguntarnos si es posible articular una negociación colectiva homogénea, sin adjetivos, que englobe tanto a quienes desarrollan la prestación por cuenta ajena como quienes lo hacen por cuenta propia.

En términos generales cabría admitir la posibilidad de negociar un convenio colectivo por un sindicato que aglutinase tanto a trabajadores asalariados como a autónomos sin trabajadores por cuanto el artículo 83.1 ET señala que los convenios colectivos tendrán el ámbito de aplicación que las partes acuerden. No obstante, la ampliación del ámbito subjetivo del convenio colectivo tiene como primer obstáculo el artículo 3.1 LOLS, el cual reconoce a los autónomos sin asalariados la afiliación a un sindicato, pero no la inclusión en una parte esencial de su acción colectiva: el convenio colectivo. Esta exclusión ha intentado ser salvada mediante la formulación de diversas teorías a través de las cuales responder a la cuestión de la eficacia jurídica atribuible a las cláusulas convencionales que se refieran a los trabajadores autónomos ${ }^{31}$ si bien la tesis dominante es la que los sitúa extramuros al continuar leyéndose el término "trabajador" en clave laboral. Una cuestión, necesitada de reformulación dado el contexto económico en el que actualmente nos movemos, por lo que debemos apostar por considerar el término trabajador en un sentido sociológico, "como persona que vive habitualmente de su trabajo" 32 lo cual permitiría soslayar los inconvenientes que tradicionalmente se han

\footnotetext{
${ }^{29}$ La autora, en referencia a los autónomos dependientes pero extensible en nuestra opinión a los nuevos tipos de autónomos digitales, aboga por "un modelo alternativo de presencia sindical directa a través de nuevos sujetos sindicales cuya representación y tutela se extendiera a las diversas formas de trabajo concurrente". SÁEZ LARA, C., "La representación colectiva de los trabajadores en la empresa", Revista del Ministerio de Trabajo y Asuntos Sociales, $\mathrm{n}^{\circ}$ 58, 2005, p. 327.

${ }^{30}$ Una muestra de estas referencias convencionales a los trabajadores autónomos en BARRIOS BAUDOR, G.L., "Límites a la negociación colectiva" profesional" en el ámbito del trabajo autónomo: el Derecho de la competencia", Comunicación presentada a las XXVIII Jornadas Catalanas de Derecho Social, Barcelona, 2017, p. 18 (disponible en: iuslabor.org).

${ }^{31}$ Un análisis de las propuestas realizadas en Selma Penalva, A., "La negociación colectiva de los trabajadores autónomos", Revista de Derecho Social, nº 46, 2009, p. 210-214.

${ }^{32}$ VIDA SORIA, J., "Artículo 28.1", en AlZaGa VillaAmIL (Director), Comentarios a las Leyes Políticas, Editoriales de Derecho Reunidas (Edersa), Madrid, 1983, p.217. Por su parte GutIÉRREZ-SOLAR CALVO se interroga acerca de la existencia o no de un concepto constitucional de trabajador que integre a los autónomos a efectos de su inclusión en la negociación colectiva, planteando en caso negativo que "el principal apoyo para el reconocimiento de la negociación colectiva vendría dado por los artículos 1 y 9.2 CE reguladores de la igualdad real". GUTIÉRREZ-Solar CALVO, B., "La negociación colectiva de los autónomos", en VALDÉS DAL-RÉ (Director), LAHERA ForTEZA (Coordinador), Manual jurídico de negociación colectiva, La Ley, Madrid, 2008, p. 1369.
} 
planteado a la aplicación de los convenios colectivos a los trabajadores autónomos afiliados al sindicato negociador.

Un segundo obstáculo vendría de la mano del Derecho de la Competencia. La jurisprudencia comunitaria se ha mostrado contraria a la inclusión en el ámbito de aplicación de los convenios colectivos de los trabajadores autónomos. Así en el Asunto FNV Kunsten Informatie en Media ${ }^{33}$ el convenio colectivo fijaba los honorarios de los músicos de orquesta, tanto asalariados como autónomos, afiliados al mismo sindicato firmante. Al valorar si esa regulación homogénea vulneraba la normativa sobre competencia en relación a los trabajadores autónomos el Tribunal europeo considera que al tratarse de operadores económicos independientes que ofrecen sus servicios a un determinado mercado a cambio de una remuneración, respecto de ellos rige el contenido del artículo 101.1 TFUE. Además, niega al sindicato pactante tal consideración, señalando que cuando actúa como representante de los trabajadores autónomos a él afiliados su condición no es la de interlocutor social pasando a ser la de asociación empresarial. De este modo cierra las puertas a una determinación homogénea de condiciones de trabajo entre prestadores asalariados y autónomos mediante su inclusión en el ámbito de aplicación del mismo convenio colectivo. Más acertadas nos parecen las conclusiones del Abogado General Sr. Wahl quien considera que la eliminación de la competencia en materia salarial, fruto de una regulación convencional homogénea de estas condiciones para trabajadores autónomos y asalariados, implica que el empresario no puede contratar ni a unos ni a otros por debajo del salario fijado en el convenio, previniéndose así el dumping social "un objetivo que los convenios colectivos que contienen normas que afectan a los trabajadores autónomos pueden perseguir legítimamente y que puede constituir uno de los elementos esenciales de la negociación" 34 .

Debe tenerse en cuenta que el artículo 101.3 TFUE excluye la prohibición cuando el acuerdo que mejore la producción o distribución de productos fomente el progreso técnico y económico y reserve a los usuarios una participación equitativa en el beneficio resultante. La fijación de un suelo de contratación para los trabajadores digitales sometidos a esta debilidad contractual daría cumplimiento a esta previsión, evitando la realización de prestaciones de servicios a la baja.

\footnotetext{
${ }^{33}$ STJUE de 4 de diciembre de 2014. En ella se plantea la posible vulneración de las normas sobre competencia en el caso de un convenio colectivo que fijaba los honorarios de los trabajadores autónomos que fuesen contratados para sustituir a trabajadores asalariados prestando unos y otros los mismos servicios y estando todos ellos representados por el mismo sindicato firmante del convenio.

${ }^{34}$ Conclusiones del Abogado General Sr. Nils Wahl presentadas el 11 de septiembre de 2014, apdo. 79. Disponible en eur-lex.europa.eu.
} 
En definitiva, el TJUE únicamente considera la posibilidad de excluir el convenio colectivo del ámbito del artículo 101.1 TFUE cuando el destinatario de dicha regulación sea un falso autónomo, es decir, un trabajador que se encuentra en una situación comparable a la de los trabajadores por cuenta ajena que presten servicios para el mismo empresario. Hubiera sido deseable que sin tener que recurrir a la falsa autonomía la inclusión de los trabajadores autónomos en el ámbito de aplicación de los convenios colectivos sería una buena forma de luchar contra la conversión forzada de asalariados en trabajadores autónomos. Esta y otras sentencias que con anterioridad resolvieron sobre el contenido del artículo 101.1 TFUE conforman una jurisprudencia en la que se aprecia como "el principio laboriosamente forjado en el siglo XX, según el cual el mantenimiento de la competencia entre empresas no debería entrañar un retroceso de la condición salarial, se desvía hacia un camino cada vez más transitado en dirección opuesta, ${ }^{, 35}$.

En el plano interno, la atribución de la defensa colectiva de los trabajadores autónomos a los sindicatos (artículo 19.4 LETA), promoviéndose su integración en la negociación colectiva permitirá, al tener una visión más amplia de las nuevas formas de prestación existentes, ir sentando las bases para la conformación de un concepto de empresa digital que la desvincule de la empresa tradicional, acreedora de nuevas obligaciones y generadora de nuevas formas de subordinación. La protección conjunta de trabajadores autónomos y asalariados afiliados al mismo sindicato y que prestan servicios en similares condiciones permitirá responder mejor a sus necesidades, abandonándose "un modelo representativo sometido a una parcelación inoperante" en beneficio de "un sistema sindical de coordinación que garantice una representación y acción colectiva eficaz" ${ }^{36}$. Debemos tener en cuenta que asistimos a nuevas formas de prestación en las que, junto a una jornada de trabajo en la que no existe límite máximo, las condiciones económicas unilateralmente fijadas por la plataforma digital son a menudo modificables a la baja al no estar sometidas a un salario mínimo ${ }^{37}$.

\footnotetext{
${ }^{35}$ ESCRIBANO GUTIÉRREZ, J. citando a LyON-CAEN, "Convenio colectivo y libre competencia en el ámbito de la Unión Europea: el supuesto de los trabajadores autónomos incluidos en convenio", La Ley Unión Europea, no 24, 2015, p. 16 [versión digital La Ley].

${ }^{36}$ SÁEZ LARA, C.: La representación colectiva de los trabajadores..., op. cit., p. 328.

${ }^{37}$ Señala el abogado General Sr. Wahl en sus conclusiones que "[o]tro motivo es que la posibilidad de que disponen los empresarios de sustituir a trabajadores asalariados por otras personas con respecto a las cuales no están obligados a respetar las condiciones laborales establecidas en el correspondiente convenio colectivo puede debilitar de forma sustancial la posición negociadora de los trabajadores por cuenta ajena. Por ejemplo, es difícil de imaginar que los trabajadores soliciten un incremento salarial si saben que pueden ser rápida y fácilmente sustituidos por trabajadores autónomos que probablemente realizarán el mismo trabajo por una retribución menor", op. cit. apdo. 77.
} 
En un contexto económico en el que se impone la precarización, las situaciones de debilidad contractual adquieren diversos matices. Apostar por la fijación en convenio colectivo de unas condiciones mínimas de realización del trabajo independientemente de la calificación jurídica del prestador supondría limitar no solo la expansión de la falsa autonomía, sino que permitiría evitar la progresiva devaluación del propio trabajo autónomo. Quizá solo desde un cambio en la forma de entender el trabajo en la sociedad actual puede avanzarse hacia una respuesta que satisfaga la necesidad de protección colectiva de estos nuevos trabajadores. Máxime si tenemos en cuenta los beneficios sociales que ello puede reportar.

El recurso al trabajo en régimen de autonomía, tanto cuando las condiciones de prestación están próximas a la laboralidad como cuando deben ser materialmente autónomas por las condiciones en las que se desarrolla, está falto de una adecuada regulación ${ }^{38}$. Y es esta ausencia la que está provocando no solo un aumento de falsos autónomos sino también una disminución de las condiciones en las que puede desarrollarse el trabajo por cuenta propia.

\section{Bibliografía}

AgOte, R., "On demand economy: 10 claves de entendimiento laboral", Iuslabor, $\mathrm{n}^{\mathbf{0}}$ 1, 2017.

Álvarez Del Cuvillo, A., "El centro de trabajo como unidad electoral: un concepto jurídico indeterminado en un contexto de cambio organizativo", Revista Española de Derecho del Trabajo, $\mathrm{n}^{\circ}$ 8, 2016.

BARRIOS BAUDOR, G. L., "Límites a la negociación colectiva” profesional” en el ámbito del trabajo autónomo: el Derecho de la competencia", Comunicación presentada a las XXVIII Jornadas Catalanas de Derecho Social, Barcelona, 2017 (disponible en: iuslabor.org).

Beltrán de Heredia Ruíz, I., "Economía de las plataformas y contrato de trabajo", Ponencia realizada en las XXIX Jornadas Catalanas de Derecho Social, Barcelona,

\footnotetext{
${ }^{38}$ Con relación al contenido de la STJUE de 4 de diciembre de 2014, Escribano Gutiérrez apunta que la determinación del alcance de la exclusión en la aplicación del artículo 101.1 TFUE es particularmente peligrosa si se pone en relación con el derecho de los trabajadores autónomos dependientes económicamente a negociar colectivamente sus condiciones de trabajo con la empresa, por cuanto esa negociación "entraría de lleno en la prohibición contenida en tal precepto. Se trataría de un simple acuerdo entre empresas destinado a falsear la competencia, y por tanto sería nulo". EsCRIBANO GuTIÉRREZ, J., "Convenio colectivo y libre competencia en el ámbito de la Unión Europea...”, op. cit., p. 15 de la versión digital.
} 
2018, Blog "Una mirada crítica a las relaciones laborales" [en línea], disponible en https://ignasibeltran.com/2018/02/07/economia-de-las-plataformas-platform-economyy-contrato-de-trabajo-ponencia.

CRUZ VILlalón, J., "La tutela colectiva por los trabajadores autónomos de sus intereses profesionales”, Relaciones Laborales, nº 7, 1999 (versión digital).

DAGNINO, E., "Uber Law: perspectiva jurídico-laboral de la sharing/on demand economy", Revista Internacional y Comparada de Relaciones Laborales y Derecho del Empleo, $\mathrm{n}^{\circ}$ 3, 2015.

ESCRIBANO GutiÉRREZ, J., "Convenio colectivo y libre competencia en el ámbito de la Unión Europea: el supuesto de los trabajadores autónomos incluidos en convenio", La Ley Unión Europea, no 24, 2015 [versión digital La Ley].

EstebAn LEGARRETA, R., "Cuestiones sobre la articulación de la representación del personal al servicio de plataformas colaborativas", en Descentralización productiva: nuevas formas de trabajo y organización empresarial, Cinca, Madrid, 2018.

GARRIDO PÉREZ, E., "La representación de los trabajadores al servicio de plataformas colaborativas", Revista de Derecho Social, nº 80, 2017.

GINÈS I FABRELlAS, A., "Crowdsourcing sites y nuevas formas de trabajo. El caso de Amazon Mechanical Turk", Revista Derecho Social y Empresa, nº 6, 2016.

GUERRERO VizUete, E., "La economía digital y los nuevos trabajadores: un marco contractual necesitado de delimitación”, Revista de Relaciones Laborales y Derecho del Empleo, vol. 1, nº 1, 2018.

GUERRERO VIzUETE, E., El trabajador autónomo dependiente económicamente: un estudio jurídico laboral, Lex Nova- Thomson Reuters, Valladolid, 2012.

GutiÉRrez-Solar CALvo, B., "La negociación colectiva de los autónomos", en VALDÉS DAL-RÉ (Director), LAHERA FORTEZA (Coordinador), Manual jurídico de negociación colectiva, La Ley, Madrid, 2008.

Mercader UGuina, J. R., "El nuevo modelo de trabajo autónomo en la prestación de servicios a través de plataformas digitales", Diario La Ley, n 9, 2017. 
Montero PASCUAL, J.J., "La regulación de la economía colaborativa", en MONTERO PASCUAL (Director), La regulación de la economía colaborativa. Airbnb, Blablacar, Uber y otras plataformas, Tirant lo Blanch, Valencia, 2017.

OJeDA AvilÉs, A., La deconstrucción del Derecho del Trabajo, La Ley, Madrid, 2010.

SÁEz LARA, C., "La representación colectiva de los trabajadores en la empresa", Revista del Ministerio de Trabajo y Asuntos Sociales, $\mathrm{n}^{\circ}$ 58, 2005.

SÁNCHEZ-URÁN AZAÑA, Y., "Economía de plataformas digitales y servicios compuestos. El impacto en el Derecho, en especial, en el Derecho del Trabajo", La Ley Unión Europea, no 57, 2018 (versión digital La Ley).

Selma Penalva, A., "La negociación colectiva de los trabajadores autónomos", Revista de Derecho Social, no 46, 2009.

SORIA BARTOlOMÉ, B., "Aspectos económicos de la economía colaborativa" en Montero Pascual (Director), La regulación de la economía colaborativa. Airbnb, Blabacar, Uber y otras plataformas, Tirant lo Blanch, Valencia, 2017.

Todolí Signes, A., El trabajo en la economía colaborativa, Tirant lo Blanch, Valencia, 2016.

TriLlo, F., "Relaciones de trabajo en la economía digital", Revista de Derecho Social, $n^{\circ} 76,2016$.

VIDA Soria, J., “Artículo 28.1” en Alzaga VillaAmil (Director), Comentarios a las Leyes Políticas, Editoriales de Derecho Reunidas (Edersa), Madrid, 1983. 
Fecha recepción: 9.1.2019 Fecha aceptación: 15.1.2019 